\title{
Design and performance evaluation of a PV interface system based on inductive power transfer
}

\author{
Ahmed Ragab, Mostafa I. Marei, Mohamed Mokhtar, Ahmed Abdelsattar \\ Electrical Power and Machine Department, Ain Shams University, Cairo, Egypt
}

\begin{tabular}{l}
\hline \hline Article Info \\
\hline Article history: \\
Received Jun 15, 2020 \\
Revised Jan 5, 2021 \\
Accepted Jan 27, 2021 \\
\hline Keywords: \\
Double-sided LCC compensation \\
MPPT control \\
PV \\
Wireless power transfer \\
Zero voltage switching
\end{tabular}

\footnotetext{
Corresponding Author:

Ahmed Ragab

Department of Electrical Power and Machines

Ain Shams University

Cairo, Egypt

Email: ahmed.ragab.mohamed.lotfy@gmail.com
}

\begin{abstract}
This paper presents a photovoltaic (PV) based battery charger utilizing a wireless power transfer (WPT) interface system. The double-sided inductorcapacitor-capacitor (LCC) compensation network is utilized for the inductive power transfer (IPT) system. Because of nonlinear characteristics of the PV, the maximum power point tracking (MPPT) is achieved by controlling the phase displacement angle or the pulse width of the quasi-square pulse inverter connected to the transmitting coil of the IPT system. As a result, the power transferred to the secondary-side, which is connected to a battery bank, is regulated. The IPT-based PV interface system is designed to achieve zero voltage switching (ZVS) in the primary side at rated conditions to minimize the switching loss. Extensive simulation studies are carried out using EMTDC/PSCAD software to investigate the dynamic performance of the proposed IPT-based PV interface system.
\end{abstract}

This is an open access article under the CC BY-SA license.

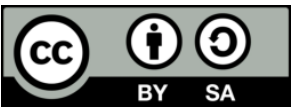

\section{INTRODUCTION}

Wireless power transfer (WPT) is the operation of transferring power from circuit to another without passing through any conductive elements connecting them. This technology of WPT is widely used in biomedical implants (several watts), electrical vehicle charger (several kilowatts), and railway vehicles (several megawatts) with high efficiency in some prototype systems [1]-[8]. Many schemes for WPT have been provided such as capacitive, inductive, microwave, and laser. Inductive Power Transfer (IPT) is the more popular and widely studied in the last two decades. The IPT system contains an air core transformer with leakage reactance compensation network by using capacitances.

The transmitting and receiving coils design is greatly important to overcome the smaller values of coupling coefficient $\mathrm{K}$ which is in the range (5\%-30\%). It depends on the gap between the coils, alignment, and size of primary and secondary coils [9], [10]. As a result, the mutual inductance between the two primary and secondary coils is very small but the leakage inductance is large [11]. Therefore, compensation topology is necessary to fading the leakage inductance. Many compensation circuits have been implemented to both the primary and secondary of the transformer. Literature describes four basic topologies for the connection of the compensating capacitor to the transformer which are series-series (SS), series-parallel (SP), parallel-series (PS), and parallel-parallel (PP) [12]-[14]. Some other superior topologies have been proposed in [15], [16]. The important aspect in a wireless charging system is the compensation circuit topology as it increases the ability of power transfer, LCC compensation circuit helps achieve unity power factors for both the primary 
side and secondary-side, minimizes the VA rating of the power source [17], and can achieve soft switching of the power electronics devices [18], [19].

The double-sided LCC compensation network is one of the most efficient topologies presented in literature. It is formed by inserting one inductor and two capacitors between each converter and its associated coil, as shown in Figure 1. There are three advantages for the LCC compensated converter at resonant frequency. First, reactive power in the secondary side can be compensated to form a unity power factor pickup [17]; second, the size and cost of the additional inductor are reduced compared to the LCL compensated converter [20]; third, tuning the parameters of LCC compensation networks renders the converters of the IPT system to operate at zero current switching (ZCS) [18].

Usually, resonant frequency of the IPT system changes when the coupling status changes [21]. There are two methods to maintain the resonance: frequency control and impedance matching [22]-[25]. In [22], the phase locked loop techniques are used to achieve resonant frequency. In SS structure, a tuning circuit is used for matching between resonant frequency of the resonator pair to that of the power supply and hence, increase efficiency. Similarly, an automated impedance matching (IM) system is used in [24]. For the SS structure, when adding capacitor, the resonant frequency can be achieved due to the tuning between the capacitor and coil self-inductance [26]. In addition, the resonant frequency is fully independent on the load and also coupling condition (distance, alignment, size of the coils). In the other hand, the primary current is dependent on load and coupling condition. In order to maintain primary current, additional phase shift or duty ratio control is used. As a result, the complexity level of the control system is increased and there is a possibility for a circulating current and losing soft switching. Moreover, one of the benefits of maintaining primary coil current constant is simplicity of making the coil to operate at its rated condition. In addition, the primary coil side power is easily controlled. In [27], a WPT converter is proposed for PV interfacing system. The compensation circuit consists of LC circuits on both the primary and secondary sides.

This paper presents the design and analysis of a proposed photovoltaic (PV) based battery charger utilizing the IPT system. Yet, the analysis and design of double-sided LCC compensation parameters for IPT are based on square-wave inverter [9-10]. In this paper, the pulse width of the inverter is controlled to track maximum power point (MPP) of a PV array. Consequently, the voltage waveform of the inverter becomes quasi-square. The double-sided LCC compensation parameters are designed for the proposed system. The resonant frequency of LCC compensation network is fully independent from the load and coupling condition (distance, alignment and size of the coils). A parameter tuning method is presented to achieve zero voltage switching (ZVS) for MOSFETs in the primary side to minimize the switching loss. Consequently, high efficiency can be easily achieved for the IPT system. This method is more effective for the electric vehicle charging application where the coupling coefficient is varying. Extensive simulation studies are carried out using EMTDC/PSCAD software to evaluate the dynamic performance of the proposed system.

The paper is organized as follows. Section II presents the analysis of the double-sided LCC compensation network-based IPT system and a tuning method to realize ZVS. The design of the IPT-based PV interface system is explained in Section III. Simulation results are demonstrated in Section IV. Finally, Section VI concludes the paper.

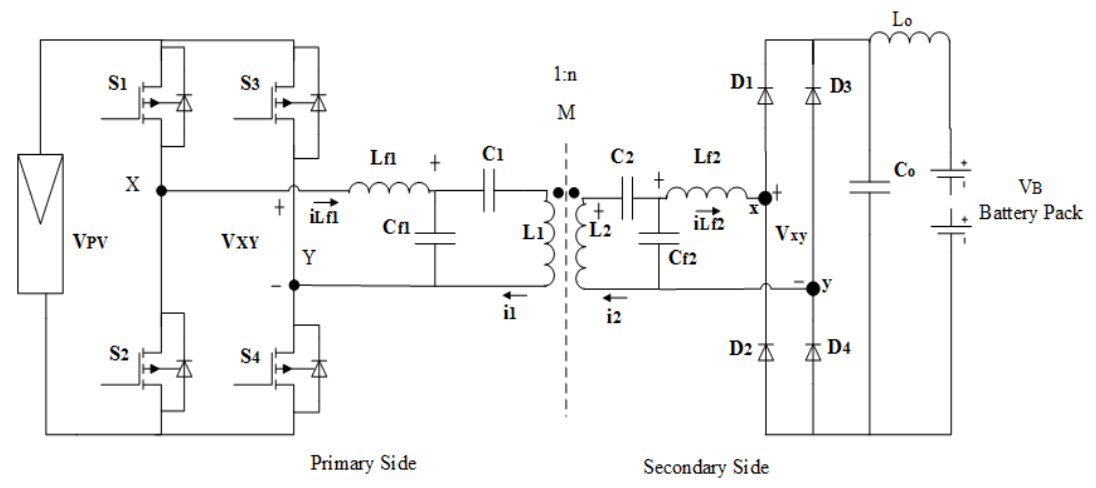

Figure 1. Double-sided LCC compensation topology-based IPT system

\section{ANALYSIS OF THE LCC COMPENSATION NETWORK}

The IPT system based on double-sided LCC compensation network is shown in Figure 1. The DC input, from the PV array, is transformed to a high frequency square wave by a full-bridge inverter, which is formed by MOSFET switches S1 to S4. At the secondary-side, diode rectifier is used to convert high

Design and performance evaluation of a PV interface system based on inductive power ... (Ahmed Ragab) 
frequency $\mathrm{AC}$ wave to $\mathrm{DC}$ again. $L_{1}$ and $L_{2}$ are the self-inductances of the primary (transmitting) and secondary (receiving) coils, respectively. $M$ is the mutual inductance between the two coils. $L_{f 1}, C_{f 1}$, and $C_{1}$ are the transmitting side compensation network. $L_{f 2}$ and $C_{f 2}$ and $C_{2}$ are the receiving side compensation components, respectively. On the primary side, $L_{f 1}, C_{f 1}, C_{1}$, and $L_{1}$ constitute the primary side resonant circuit. Here, $V_{X Y}$ is the output voltage from the inverter stage, and $V_{x y}$ is the input voltage to the rectifier. $i_{1}, i_{2}, i_{l f 1}$ and $i_{l f 2}$ are the currents of $L_{1}, L_{2}, L_{f 1}$, and $L_{f 2}$, respectively.

To simplify the analysis, the inductors and capacitor are assumed ideal. The equivalent circuit of the IPT system referred to primary side is shown in Figure 2. The turns ratio between secondary and primary is defined as (1):

$$
n=\sqrt{L_{2} / L_{1}}
$$

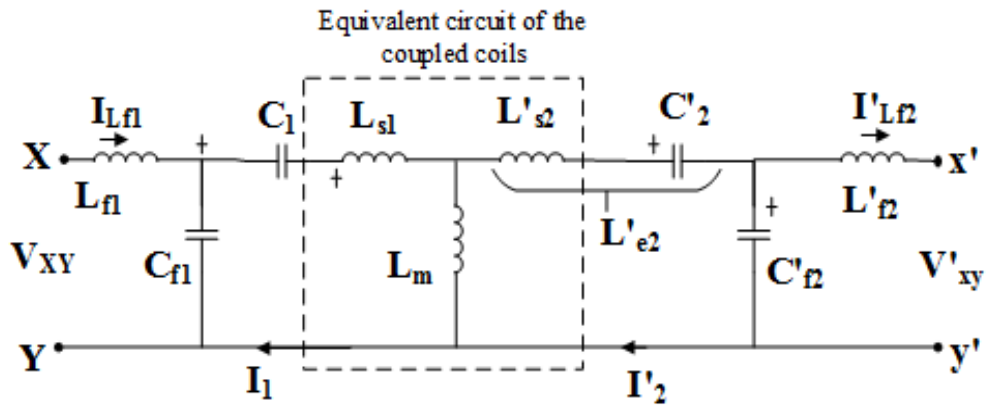

Figure 2. Equivalent circuit of the double-sided LCC compensation network referred to the primary side

The mutual and leakage inductances are given by (2):

$$
\begin{aligned}
& L_{m}=K \cdot L_{1} \\
& L_{s 1}=(1-K) \cdot L_{1} \\
& L_{s 2}^{\prime}=(1-K) \cdot \frac{L_{2}}{n^{2}}
\end{aligned}
$$

At resonant, the voltage $V_{X Y}$ and current $I_{L f l}$ are in phase. To realize a constant resonant frequency, $\omega_{r}$, the parameters of the LCC network are designed according to (3) [9]

$$
L_{f 1} C_{f 1}=L_{f 2} C_{f 2}=\left(L_{1}-L_{f 1}\right) C_{1}=\left(L_{2}-L_{f 2}\right) C_{2}=\frac{1}{\omega_{r}^{2}}
$$

It is noteworthy that $\omega_{r}$ is independent of coupling coefficient $K$ and load condition. At the resonant frequency, the power transfer through the double-sided LCC network can be calculated from (4) [9]

$$
P=V_{X Y} \cdot I_{l f 1}=\frac{\sqrt{L_{1} L_{2}}}{\omega_{r} L_{f 1} L_{f 2}} \cdot K \cdot V_{X Y} \cdot V_{x y}
$$

where $V_{X Y}$ and $V_{x y}$ are the fundamental component rms values of the input and output voltages, respectively. As shown, the transfer power is proportional to the input voltage $V_{X Y}$, coupling coefficient $k$, and the output voltage $V x y$. Hence, the output power can be controlled by adding buck or boost converter at the primary side before inverter or at the secondary side after rectifier.

The switching loss occurs at the transition period from on to off and vice versa. Higher switching frequency leads to an increase in the switching loss. The ZVS and ZCS techniques are used to reduce switching losses. However, the ZVS condition is more popular to use. The turn-off losses are very small due to the parasitic capacitance of the MOSFET which causing zero voltage across the MOSFET during turn-off transition [28]. However, ZVS operation is important during turn-on transition to minimize diode reverse recovery losses as well as the losses resulting from the parasitic capacitor of MOSFET switch. Hence, the diode shall conduct before MOSFET to achieve ZVS. Accordingly, the MOSFET shall operate at a negative 
current. Therefore, the current must lag the voltage. In this case, the input impedance of the full bridgeconverter shall be inductive to realize ZVS. To simplify the analysis, the equivalent inductance of the series branch including $L^{\prime}$ s 2 and $C^{\prime} 2$ is represented by $L^{\prime} \mathrm{e} 2$ as shown in Figure 2.

In an inverter leg, if one MOSFET is turned-off at positive current, the other MOSFET in the same leg achieves ZVS at turn-on [9]. One of the methods used to realize positive turn-off current is increasing the value of $L^{\prime} \mathrm{e} 2$ by $\Delta L^{\prime} \mathrm{e} 2$. Hence, the ZVS can be achieved at minimum turn-off current. The minimum MOSFET turn-off current is given by (5) [29]

$$
I_{O F F_{-} \min }=\frac{\sqrt{2} V_{x y \_} \min }{\omega_{r} L_{f 2}} \sqrt{\frac{\Delta L_{e 2}}{L_{f 1}}-\frac{1}{4} \frac{L_{f 2}}{L_{f 1}}}
$$

where $V_{x y \_ \text {min }}$ is the minimum rms voltage at the rectifier terminals. Therefore, to realize ZVS by minimizing the MOSFET turn-off current, $\Delta L_{e 2}$ can be obtained from (6)

$$
\Delta L_{e 2}=\frac{1}{4} L_{f 2}+\frac{I_{O F F_{-} \min }^{2} \omega_{r}^{2} L_{f 1} L_{f 2}^{2}}{2 V_{x y \_}^{2} \min } .
$$

Once the minimum turn-off current is obtained, $\Delta L_{e 2}$ can be designed. The turn-off current shall be large enough to discharge MOSFET capacitance within the dead time which can be determined by (7) [29],

$$
I_{O F F} \geq \frac{4 C_{O S S} V_{X Y \_m a x}}{t_{d}}
$$

where $V_{X Y_{-} \max }$ is the maximum input voltage, $C_{o s s}$ is the MOSFET capacitance, and $t_{d}$ is the dead time.

The change in the equivalent inductance, $\Delta L_{e 2}$ can be achieved by tuning either the leakage inductance $L_{s 2}$ or $C_{2}$. However, $L_{s 2}$ is related to the coupling coefficient which is difficult to tune. Instead, the value of $C_{2}$ is changed to achieve the desired $\Delta L_{e 2}$ as (8):

$$
\Delta L_{e 2}=\frac{1}{\omega_{r}^{2} C_{2}}-\frac{1}{\omega_{r}^{2}\left(C_{2}+\Delta C_{2}\right)}
$$

Then, the variation of $C_{2}$ can be obtained (9):

$$
\Delta C_{2}=\frac{\omega_{r}^{2} C_{2}^{2} \Delta L_{e 2}}{1-\omega_{r}^{2} C_{2} \Delta L_{e 2}}
$$

Finally, the value of $C_{2}$ is tuned at larger value that calculated by (3). When misalignment takes place between the transmitting and receiving coils, the coupling coefficient $k$ decreases. Hence, the power transfer decreases according to (4). However, the turn-off current is independent of coupling coefficient as indicated in (5). Therefore, if the tuning circuit is designed, the ZVS is achieved independent on the coupling condition.

\section{DESIGN OF LCC COMPENSATED IPT FOR PV SYSTEM}

The $P-V$ characteristic of $\mathrm{PV}$ modules is nonlinear. Due to varying of both irradiance and temperature, the maximum power produced is changed. Since the conversion efficiency of PV modules is very low, it is required to use maximum power point tracking (MPPT) control techniques [30]-[34]. The Perturb and Observe technique is used for MPPT due to its simplicity. The PV terminal voltage and current are the input to the Perturb \& Observe technique which set the duty cycle of the inverter [35]-[37]. The phase displacement technique is utilized to generate the gating signals for the inverter MOSFETs. The PV array, considered in this study, consists of two strings where each string includes six PV modules connected in series. The parameters of the PV module are given in Table 1.

According to the PV module parameters given in Table 1, the maximum power that can be transfer by the IPT is $3660 \mathrm{~W}$ and the input voltage range is less than $370 \mathrm{~V}$. A $3.66 \mathrm{~kW}$ IPT system is designed in this section according to the analysis presented in the previous section. The parameters of IPT system are shown in Table 2. Since the ratio between transmitted voltage and received voltage is around 1, the selfinductances of the transmitting coil and receiving coil are selected to have the same value.

Table 1. Parameters of PV module

Table 2. WPT system specifications 


\begin{tabular}{ll}
\hline Maximum power at STC & $305 \mathrm{~W}$ \\
Open circuit voltage & $64.2 \mathrm{~V}$ \\
Short circuit current & $5.96 \mathrm{~A}$ \\
Voltage at MPP & $54.7 \mathrm{~V}$ \\
Current at MPP & $5.58 \mathrm{~A}$ \\
No. of cells connected in series/module & 96 \\
No. of modules connected in series/array & 6 \\
No. of strings in parallel/array & 2 \\
\hline
\end{tabular}

\begin{tabular}{cc}
\hline Specification / parameter & Value \\
\hline Input Voltage & $<385 \mathrm{~V}$ \\
Output battery voltage & $300 \mathrm{~V} \sim 450 \mathrm{~V}$ \\
Coupling coefficient & $0.18 \sim 0.32$ \\
Transmitting coil inductance: $L_{f 1}$ & $360 \mu \mathrm{H}$ \\
Receiving coil inductance: $L_{f 2}$ & $360 \mu \mathrm{H}$ \\
Switching frequency & $70 \mathrm{kHz}$ \\
Maximum power & $3.66 \mathrm{~kW}$ \\
\hline
\end{tabular}

Because of the distance between the coils and misalignment, there is a range for the coupling coefficient. The maximum value is considered in the design. Moreover, the duty cycle is assumed unity at the maximum power transfer. Consequently, the output voltage from the inverter is square waveform where the rms fundamental component, at the switching frequency, can be calculated from (10),

$$
V_{X Y}=\frac{2 \sqrt{2}}{\pi} V_{M P P}
$$

where $V_{M P P}$ is the PV voltage corresponds to the MPP at standard conditions. Similarly, the rms fundamental component of the voltage at the rectifier-side is given by (11),

$$
V_{X Y}=\frac{2 \sqrt{2}}{\pi} V_{B}
$$

where $V_{B}$ is the nominal battery voltage at the output terminals of the system. Accordingly, the inductance values of the LCC compensation network is calculated from (4) as (12):

$$
L_{f 1}=L_{f 2}=\sqrt{\frac{K_{\max } V_{X Y} V_{x y}}{\omega_{r} P_{\max }} L_{1}}=\sqrt{\frac{0.32 \times \frac{2 \sqrt{2}}{\pi} \times 320 \times \frac{2 \sqrt{2}}{\pi} \times 400}{2 \pi \times 70 \times 10^{3} \times 3660} 360 \times 10^{-6}} \quad \approx 86 \mu \mathrm{H} .
$$
(3) as (13):

As the value of $L_{f 1}$ and $L_{f 2}$ are equal, the value of $C_{f 1}$ and $C_{f 2}$ are equal and can be calculated from

$$
C_{f 1}=C_{f 2}=\frac{1}{\omega_{r}^{2} L_{f 1}} \approx 60 \mathrm{nF} .
$$

In the same time, the value of $C_{1}$ and $C_{2}$ are equal and can be calculated from (3) as (14):

$$
C_{1}=C_{2}=\frac{1}{\omega_{r}^{2}\left(L_{1}-L_{f 1}\right)} \approx 19 n F
$$

The variation of $\Delta L_{e 2}$ is designed to achieve ZVS and minimize switching losses. Fairchild FCH041N60E MOSFET switches are considered which is rated at $600 \mathrm{~V}$ and 48A. According to data sheet, the output capacitance of the MOSFET $\mathrm{C}_{\mathrm{oss}}$ is $735 \mathrm{pF}$. Assuming a dead time of $600 \mathrm{~ns}$, the turn-off current should be taken higher than 1.87A as estimated from (7). Therefore, the minimum turn-off current $I_{\text {OFF }}$ min is selected to be $3 \mathrm{~A}$ to guarantee discharging of the MOSFET capacitance during the dead-time which leads to ZVS for the other MOSFET in the same inverter leg.

The value of $\Delta L_{e 2}$ is calculated from (6) as (15):

$$
\Delta L_{e 2}=\frac{1}{4} L_{f 2}+\frac{I_{O F F_{-} \min }^{2} \omega_{r}^{2} L_{f 1} L_{f 2}^{2}}{2 V_{x y \_}^{2} \min }=\left(\frac{86 \times 10^{-6}}{4}+\frac{3^{2}(2 \pi \times 70000)^{2}\left(86 \times 10^{-6}\right)^{3}}{2\left(\frac{2 \sqrt{2}}{\pi} 300\right)^{2}}\right) \approx 29 \mu H
$$

Finally, $\Delta C_{2} \approx 2.2 n F$ as estimated from (9). In [38], it is shown that in order to achieve ZVS, the capacitor $C_{2}$ is tuned at $8 \%$ to $11 \%$ larger than the calculated value.

\section{SIMULATION RESULTS}


EMTDC/PSCAD software is used to simulate the IPT system based on double sided LCC compensation network shown in Figure 1 with the design parameters presented in section III. The output filter inductor $L_{o}$ and capacitor $C_{o}$ are selected to be $10 \mu \mathrm{H}$ and $10 \mu \mathrm{F}$, respectively. The load is considered a battery with voltage of $400 \mathrm{~V}$. First, the waveforms of input and output voltages and currents without tuning $C_{2}$ are presented. Second, $C_{2}$ is tuned to achieve ZVS and the simulation results are presented.

The first task is dedicated to evaluate the performance of the proposed double-sided LCC compensation network based IPT system with variable duty cycles. The input supply voltage is assumed constant voltage source of $V_{P V}=320 \mathrm{~V}$. The PWM signals for the inverter switches at leg $X$ and leg $Y$ are shown in Figure 3(a) and 3(b), respectively, where the phase displacement between the two legs is $180^{\circ}$, which refers to $100 \%$ duty cycle. Figure 3(c) shows the current and voltage waveforms at the inverter terminals before the compensation network. The current and voltage waveforms after compensation network at the rectifier terminals are presented in Figure 3(d). These waveforms indicate that the phase shift between input voltage and output voltage is almost $90^{\circ}$. In this simulation scenario, the transmitting and receiving coils are fully aligned. As a result, the maximum power is transferred which is $3.66 \mathrm{~kW}$. The voltages across the inverters switches are shown in Figure 3(e) and 3(f). It is clear that the ZVS is not achieved at turn-on for any switch. For example, S1 is turned-on at positive load current which pass through it while the voltage across $\mathrm{S} 1$ is still close to the input voltage. The sinusoidal voltages across the transmitting and receiving coils and their currents are shown in Figure 4.

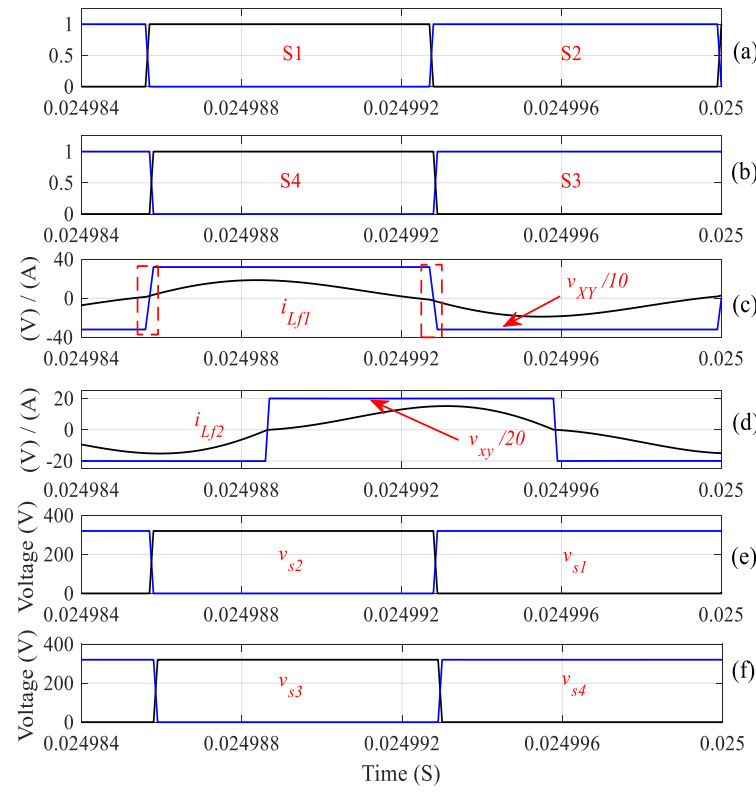

Figure 3. Performance of the double-sided LCC network-based IPT system at $100 \%$ duty ratio without tuning $\mathrm{C} 2$
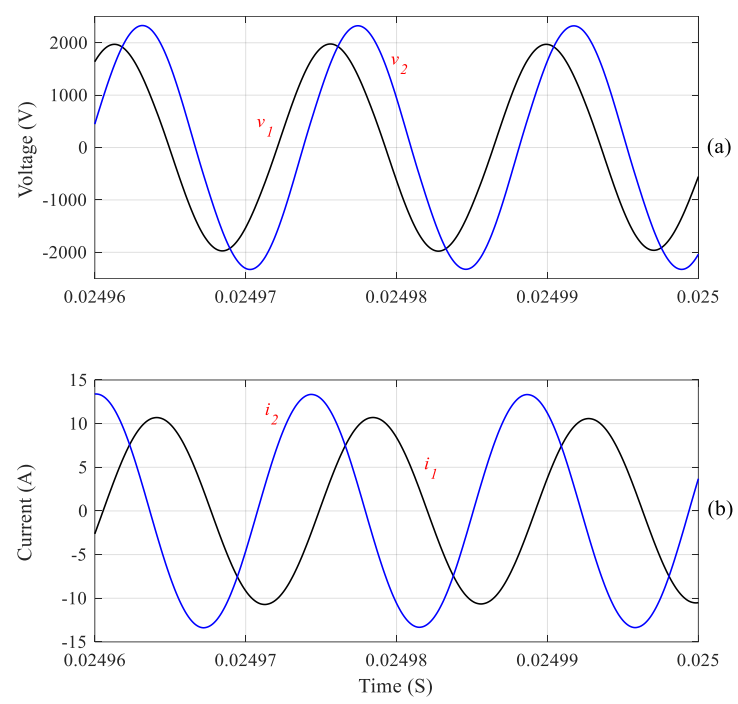

Figure 4. The voltages and currents of the transmitting and receiving coils at $100 \%$ duty ratio without tuning $\mathrm{C} 2$

Figure 5 presents the same waveforms when the value of $C_{2}$ is tuned as explained in section III to achieve ZVS. The MOSFET S2 is turned-off when the load current is negative and opposite in direction to $\mathrm{S} 1$, as illustrated in Figure 5(c). After a dead time, not simulated, the switch $\mathrm{S} 1$, in the same leg $X$, is turnedon where the current is opposite to S1. Therefore, the body diode of S1 carries the current, Figure 7. As a result, ZVS is achieved at turn-on of S1. The same behavior can be observed when S1 is turned-off and S2 is turned-on but with positive load current. Moreover, it can be observed that the switches S3 and S4 of leg $Y$ are turned-on with ZVS in a similar manner to leg $X$. As a result, the turn-on losses are eliminated and the system efficiency is enhanced. The voltages and currents of the transmitting and receiving coils are sinusoidal waveforms as demonstrated in Figure 6. 


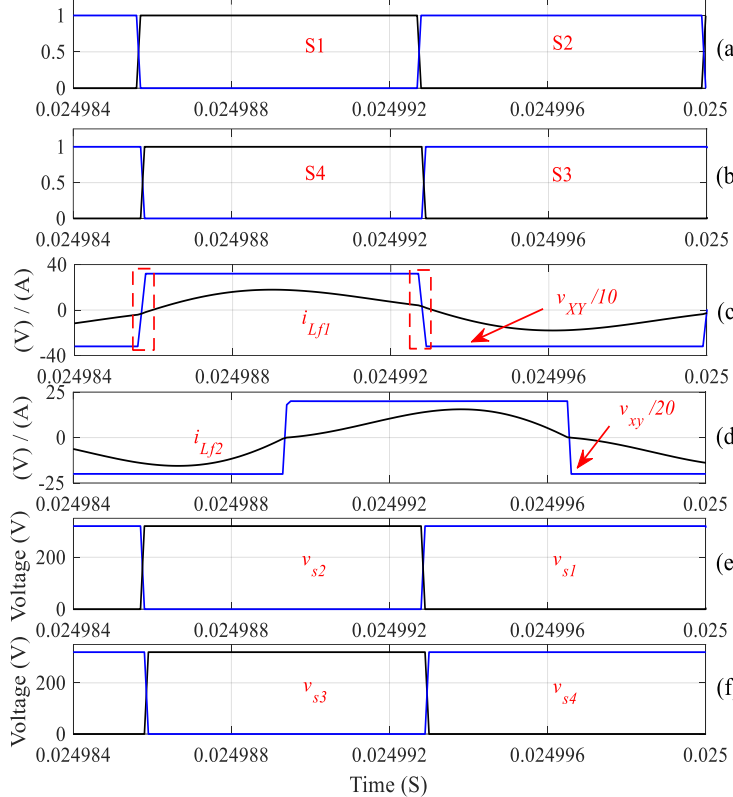

Figure 5. Performance at $100 \%$ duty ratio with tuning $\mathrm{C}_{2}$

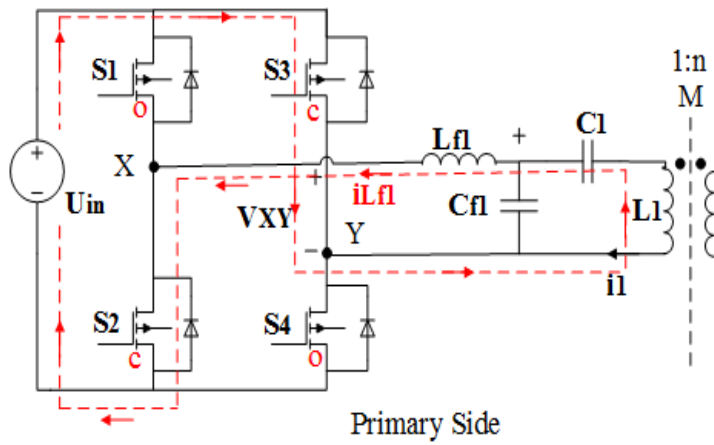

(a)
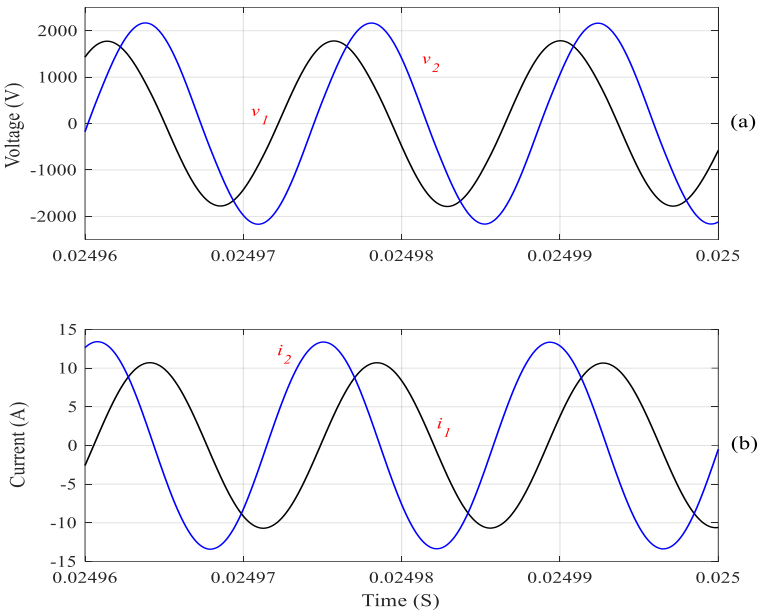

Figure 6. The voltages and currents of the transmitting and receiving coils at $100 \%$ duty ratio

At instant of switching the current still in negative direction but the switches $\mathrm{S} 2 \& \mathrm{~S} 3$ are open

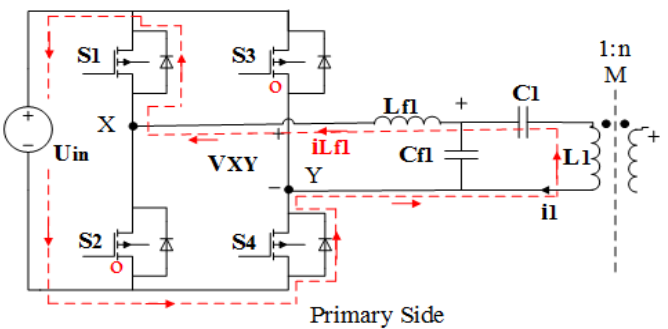

(b)

Figure 7. Current direction and switches status at $100 \%$ duty ratio with tuning $\mathrm{C}_{2}$

Figure 8 illustrates the performance when the double-sided LCC network-based IPT system is controlled at $75 \%$ duty cycle. The phase displacement between leg $Y$ and leg $X$ is $135^{\circ}$. It can be observed that the switches of leg $X, \mathrm{~S} 1$ and $\mathrm{S} 2$, are turned-on when the current opposes their directions. This action leads to ZVS as the body diodes of S1 and S2 conduct the current at their turn-on instant. However, this is not the case for the switches of leg $Y$, as either $\mathrm{S} 2$ or $\mathrm{S} 3$ is turned-on when the current direction coincides with the switch. In contrast, either S3 or S4 is turned-off when the current opposes their directions, where their body diodes are carrying the current. Therefore, the switches of leg $Y$ achieve ZVS at turn-off. Figure 9 and Figure 10 demonstrate the same dynamic behaviour of the proposed IPT system at duty ratios of 50\% and $25 \%$, respectively. Unlike for square-wave operation where ZVS is achieved for all switches of the IPT inverter, for quasi-square voltage, ZVS is attained for switches in one-leg during turn-on and for the other leg during turn-off. Reducing the duty ratio leads to discontinuity of the current input to the rectifier. During the intervals of zero current through $L_{f 2}$, the voltage across the rectifier, $v_{x y}$, becomes equal to the voltage across $C_{f 2}$ which is part from sinusoidal waveform.

The voltages across the transmitting and receiving coils and their currents are still sinusoidal regardless the value of the duty ratio as demonstrated in Figure 11 for $25 \%$ duty ratio.

The purpose of the MPPT is to adjust the PV terminal voltage at the MPP under varying atmospheric conditions by continuously varying the duty cycle of the inverter as shown in Figure 12 . In order 
to investigate the dynamic performance of the proposed IPT-based PV interface system, the irradiance is increased from $500 \mathrm{~W} / \mathrm{m}^{2}$ to $750 \mathrm{~W} / \mathrm{m}^{2}$ at $t=0.4 \mathrm{~s}$ and increased to $1000 \mathrm{~W} / \mathrm{m}^{2}$ at $t=0.7 \mathrm{~s}$ as illustrated in Figure 12(a). The MPPT controller is successfully setting the duty cycle, as depicted in Figure 12(b), for the quasi-square pulse inverter, utilized in the IPT system, which results in extracting the maximum power as demonstrated in Figure 12(c). The PV terminal voltage is shown in Figure 12(d). Figure 13 demonstrates the power-voltage trajectory of the PV array which clearly indicates the accurate and tight MPPT of the proposed IPT-based PV interface system under different conditions.

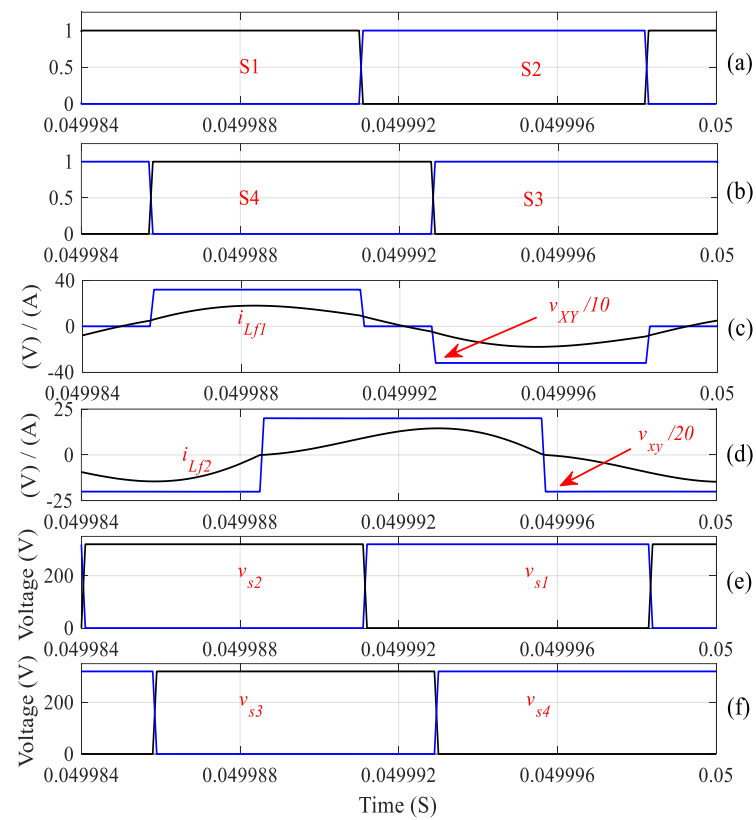

Figure 8 . Performance at $75 \%$ duty ratio with tuning $\mathrm{C}_{2}$

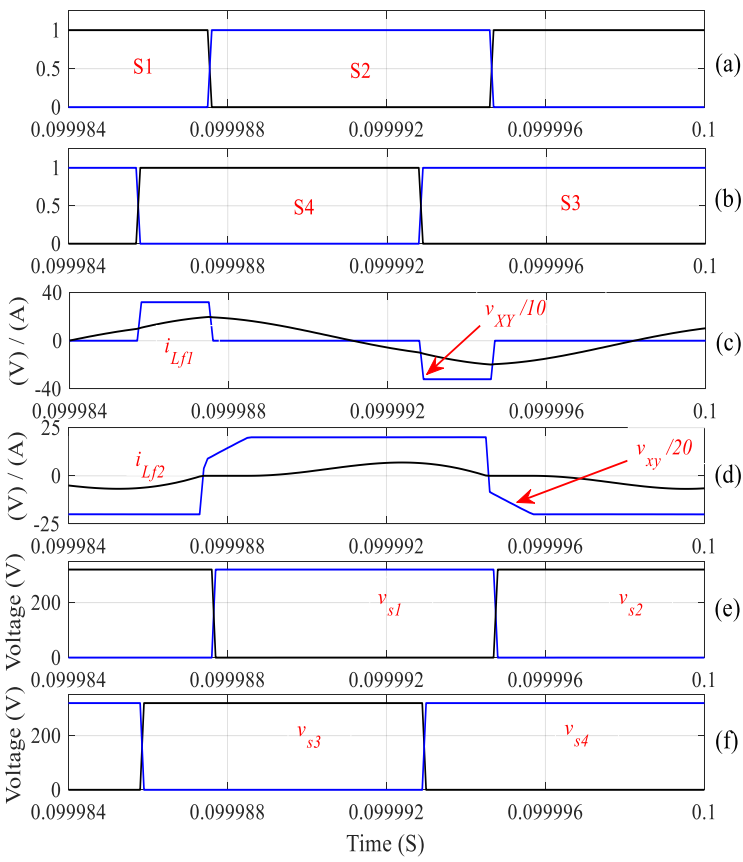

Figure 10 . Performance at $25 \%$ duty ratio with tuning $\mathrm{C}_{2}$

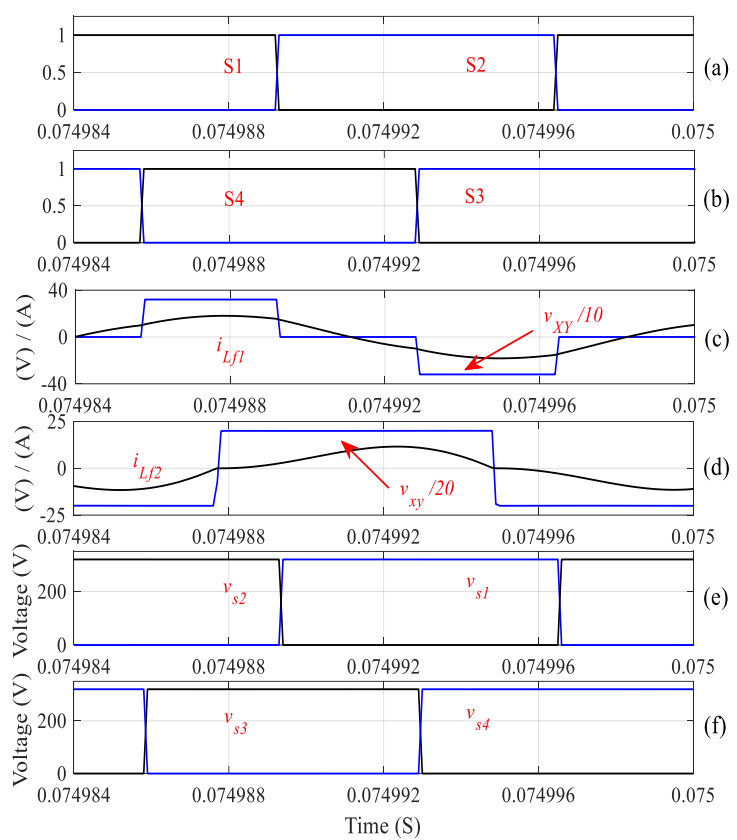

Figure 9. Performance at $50 \%$ duty ratio with tuning $\mathrm{C}_{2}$
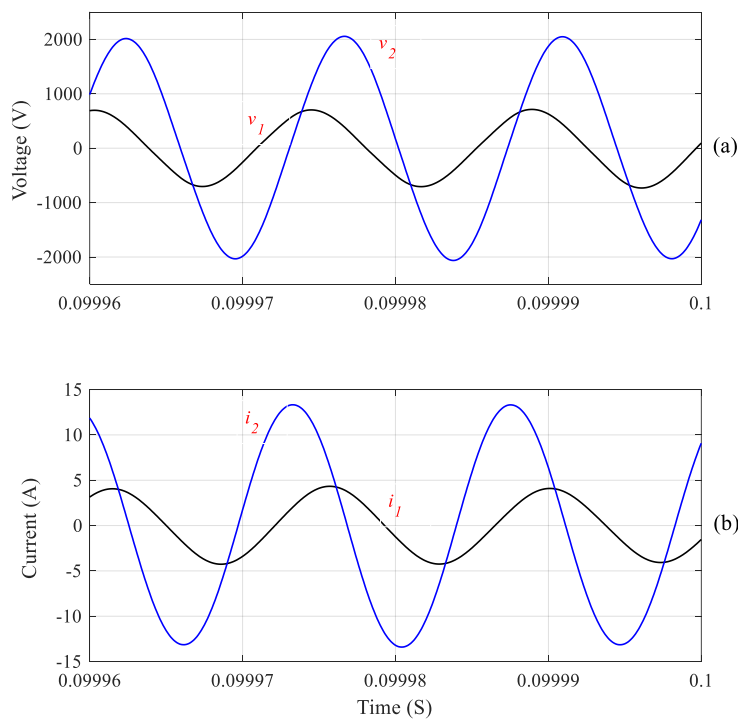

Figure 11. The voltages and currents of the transmitting and receiving coils at $25 \%$ duty ratio

Design and performance evaluation of a PV interface system based on inductive power ... (Ahmed Ragab) 

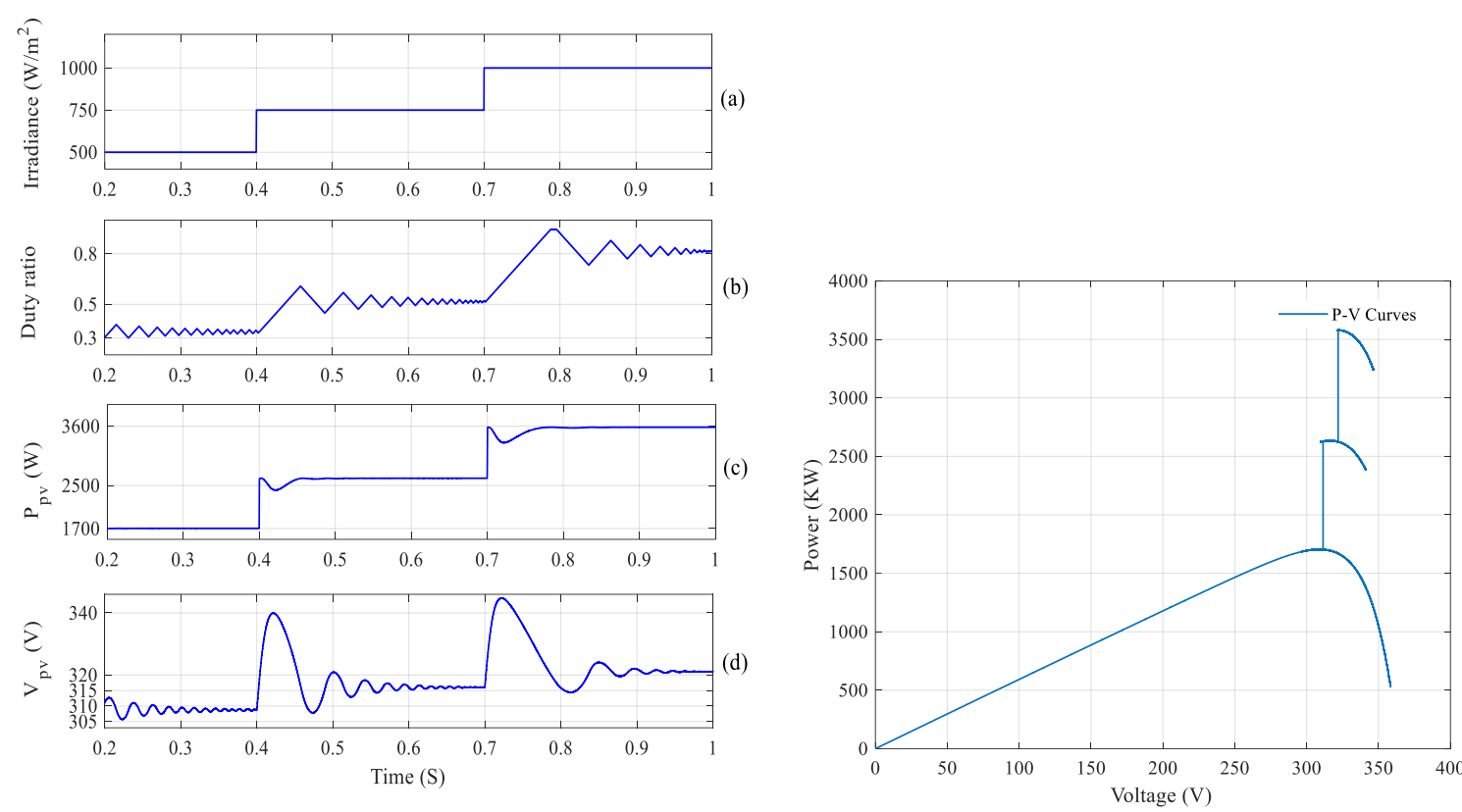

Figure 12. The duty cycle of the IPT system, the extracted power, and voltage of the PV array

Figure 13. Power-voltage trajectory of the PV arrays

\section{CONCLUSION}

In this paper, a WPT-based PV interface system is designed. The perturb and observe technique is utilized for MPPT by controlling the duty ratio of the square-wave inverter. In addition, the LCC compensation network is tuned to realize ZVS where any inverter switch is turned-on when load current opposes its direction at full duty ratio. Consequently, the body diode conducts before its MOSFET to achieve ZVS. Moreover, for quasi-square wave operation, where the duty ratio of the IPT inverter is controlled, the ZVS is attained for switches in one-leg during turn-on and for the other leg during turn-off. Simulation results are presented to validate the design of proposed PV interface system based on IPT.

\section{REFERENCES}

[1] F. Musavi and W. Eberle, "Overview of Wireless Power Transfer Technologies for Electric Vehicle Battery Charging," IET Power Electronics, vol. 7, no. 1, pp. 60-66, Jan. 2014.

[2] M. P. Kazmierkowski, R. M. Miskiewicz, and A. J. Moradewicz, "Inductive coupled contactless energy transfer systems-a review," Selected Problems of Electrical Engineering and Electronics (WZEE), Kielce, 2015, pp. 1-6.

[3] J. H. Kim et al., "Development of 1-MW Inductive Power Transfer System for a High-Speed Train," IEEE Transactions on Industrial Electronics, vol. 62, no. 10, pp. 6242-6250, Oct. 2015.

[4] R. Haldi and K. Schenk, "A $3.5 \mathrm{~kW}$ Wireless Charger for Electric Vehicles with Ultra High Efficiency," Energy Conversion Congress and Exposition (ECCE), Pittsburgh, PA, 2014, pp. 668-674

[5] R. Wu, W. Li, H. Luo, J. K. O. Sin, and C. P. Yue, "Design and characterization of wireless power links for brainmachine interface applications," IEEE Trans. on Power Electronics, vol. 29, no. 10, pp. 5462-5471, Jan. 2014.

[6] D. Ahn and P. P. Mercier, "Wireless power transfer with concurrent $200 \mathrm{kHz}$ and $6.78 \mathrm{MHz}$ operation in a single transmitter device," IEEE Transactions on Power Electronics, no. 99, pp. 1-13, Sep. 2015.

[7] A. M. Obais and A. F. Ruzij, "Design and implementation of an efficient WPT system," International Journal of Power Electronics and Drive Systems (IJPEDS), vol. 11, no. 2, pp. 711-725, Jun. 2020.

[8] I. Alhamrouni, M. Iskandar, M. Salem, L. J. Awalin, A. Jusoh, and T. Sutikno, "Application of inductive coupling for wireless power transfer," International Journal of Power Electronics and Drive Systems (IJPEDS), vol. 11, no. 3, pp. 1109-1116, Sep. 2020.

[9] S. Li, W. Li, J. Deng, T. D. Nguyen, and C. C. Mi, "A Double-Sided LCC Compensation Network and Its Tuning Method for Wireless Power Transfer," IEEE Trans. on Vehicular Technology, vol. 64, no. 6, Jun. 2015.

[10] N. T. Diep, N. K. Trung, and T. T. Minh, "Wireless power transfer system design for electric vehicle dynamic charging application," International Journal of Power Electronics and Drive Systems (IJPEDS), vol. 11, no. 3, pp. 1468-1480, Sep. 2020.

[11] T. D. Nguyen, S. Li, W. Li, and C. C. Mi, "Feasibility study on bipolar pads for efficient wireless power chargers," in Proc. 29th IEEE APEC Expo., 2014, pp. 1676-1682. 
[12] A. Khaligh and S. Dusmez, "Comprehensive topological analysis of conductive and inductive charging solutions for plug-in electric vehicles," IEEE Trans. on Vehicular Technology, vol. 61, no. 8, pp. 3475-3489, Oct. 2012.

[13] C. S. Wang, O. H. Stielau, and G. A. Covic, "Design considerations for a contactless electric vehicle battery charger," IEEE Transactions on Industrial Electronics, vol. 52, no. 5, pp. 1308-1314, Oct. 2005.

[14] M. Rehman, P. Nallagownden, and Z. Baharudin, "Efficiency investigation of SS and SP compensation topologies for wireless power transfer," International Journal of Power Electronics and Drive Systems (IJPEDS), vol. 10, no. 4, pp. 2157-2164, 2019.

[15] C. Auvigne, P. Germano, D. Ladas, and Y. Perriard, "A dual-topology ICPT applied to an electric vehicle battery charger," in Proc. 20th ICEM, 2012, pp. 2287-2292.

[16] H. H. Wu, A. Gilchrist, K. Sealy, and D. Bronson, "A 90 percent efficient $5 \mathrm{~kW}$ inductive charger for EVs," in Proc. IEEE ECCE, 2012, pp. 275-282.

[17] N. A. Keeling, G. A. Covic, and J. T. Boys, "A unity-power-factor IPT pickup for high-power applications," IEEE Trans. on Industrial Electronics, vol. 57, no. 2, pp. 744-751, Feb. 2010.

[18] Z. Pantic, B. Sanzhong, and S. Lukic, "ZCS LCC-compensated resonant inverter for inductive-power-transfer application," IEEE Transactions on Industrial Electronics, vol. 58, no. 8, pp. 3500-3510, Aug. 2011.

[19] S. Al-Chlaihawi, A. H. Tawafan, and F. K. Abd, "Experimental installation of wireless power transfer system based on the series resonance technology," International Journal of Power Electronics and Drive Systems (IJPEDS), vol. 11, no. 4, pp. 1693-1700, 2020.

[20] U. K. Madawala and D. J. Thrimawithana, "A bidirectional inductive power interface for electric vehicles in V2G systems," IEEE Trans. on Industrial Electronics, vol. 58, no. 10, pp. 4789-4796, Oct. 2011.

[21] Y. Nagatsuka, N. Ehara, Y. Kaneko, S. Abe, and T. Yasuda, "Compact contactless power transfer system for electric vehicles," in Proc. IPEC, 2010, pp. 807-813.

[22] D. A. G. Pedder, A. D. Brown, and J. A. Skinner, "A contactless electrical energy transmission system," IEEE Trans. on Industrial Electronics, vol. 46, no. 1, pp. 23-30, Feb. 1999.

[23] S. Krishnan et al., "Frequency agile resonance-based wireless charging system for electric vehicles," in Proc. IEVC, 2012, pp. 1-4.

[24] B. T. Chuan, M. Kato, T. Imura, O. Sehoon, and Y. Hori, "Automated impedance matching system for robust wireless power transfer via magnetic resonance coupling," IEEE Trans. on Industrial Electronics, vol. 60, no. 9, pp. 3689-3698, Sep. 2013.

[25] B. T. Chuan, T. Imura, M. Kato, and Y. Hori, "Basic study of improving efficiency of wireless power transfer via magnetic resonance coupling based on impedance matching," in Proc. IEEE ISIE, 2010, pp. 2011-2016.

[26] J. Huh, S. W. Lee, W. Y. Lee, G. H. Cho, and C. T. Rim, "Narrow-width inductive power transfer system for online electrical vehicles," IEEE Transactions on Power Electronics, vol. 26, no. 12, pp. 3666-3679, Dec. 2011.

[27] A. Ghosh, A. Ukil, and A. P. Hu, "Integration of Rooftop Solar PV Generation with Wireless Power Transfer," 2019 IEEE PES Asia-Pacific Power and Energy Engineering Conference (APPEEC), 2019.

[28] R. W. Erickson and D. Maksimovic, "Fundamentals of Power Electronics," 2nd ed. New York, NY, USA: Academic, 2001.

[29] L. Bing, L. Wenduo, L. Yan, F. C. Lee, and J. D. Van Wyk, "Optimal design methodology for LLC resonant converter," in Proc. 21st IEEE APEC Expo, 2006, pp. 533-538.

[30] M. AL-Emam, M. I. Marei, and W. El-khattam, "A Maximum Power Point Tracking Technique for PV Under Partial Shading Condition," in Proc. IEEE India International Conference on Power Electronics (IICPE), MNIT Jaipur, India, Dec. 2018.

[31] A. S. Hamed, M. I. Marei, and M. A. Badr, "PV interfacing system based on dual cascaded inverter," in Proc. IEEE International Conference on Renewable Energy Research and Applications (ICRERA), San Diego, CA, USA, Nov. 2017, pp. 93-100.

[32] H. M. El-Helw, M. Al-Hasheem, and M. I. Marei, "Control strategies for the DAB based PV interface system," PLoS ONE, vol. 11, no. 8, pp. 1-19, Aug. 2016.

[33] M. I. Marei, H. El-Helw, and M. Al-Hasheem, "A Grid-Connected PV Interface System Based On The DABConverter," in Proc. IEEE International Conference on Environment and Electrical Engineering (EEEIC), Rome, Italy, Jun. 2015, pp. 161-165.

[34] M. Mokhtar, M. I. Marei, and A. A. El-Sattar, "Improved Current Sharing Techniques for DC Microgrids," Electric Power Components and Systems, vol. 46, no. 7, pp. 757-767, Apr. 2018.

[35] M. I. Marei, B. Alajmi, I. Abdelsalam, and M. F. Alhajri, "A PV interface system based on high-gain highfrequency link converter," in Proc. IEEE International Universities Power Engineering Conference (UPEC), Glasgow, UK, Sep. 2018.

[36] B. Alajmi, M. I. Marei, and I. Abdelsalam, "A Multi-Port DC/DC Converter based on Two- Quadrant Inverter Topology for PV Systems," IEEE Transactions on Power Electronics, vol. 36, no. 1, pp. 522-532, Jan. 2021.

[37] H. Otmane, M. Youssef, and B. Mokhtar, "Comparative analysis of cascaded Fuzzy-PI controllers based-MPPT and perturb and observe MPPT in agrid-connected PV system operating under different weather and loading conditions," International Journal of Power Electronics and Drive System (IJPEDS), vol. 10, no. 4, pp. 1986-1994, Dec. 2019

[38] W. Li, H. Zhao, S. Li, J. Deng, T. Kan, and C. C. Mi, "Integrated LCC compensation topology for wireless charger in electric and plug-in electric vehicles," IEEE Trans. on Power Electronics, vol. 62, no. 7, pp. 4215-4225, Dec. 2014. 